\title{
Contribución al estudio de la Arqueología de la Arquitectura
}

\author{
Juan Antonio Quirós Castillo*
}

\section{INTRODUCCIÓN}

En el presente trabajo queremos plantear, dentro de los fines que persiguen las presentes jornadas, líneas de investigación que debieran ser potenciadas por la arqueología medieval, y en concreto la arqueología de la arquitectura. Son bastante frecuentes las referencias a la estratigrafía murarial, la comprensión estratigráfica global, etc., pero no existe una discusión teórica o metodológica del problema, remitiéndonos continuamente a las experiencias italianas. Sin pretender ser originales ni novedosos, creemos que sea importante empezar a contextualizar los problemas en nuestro ámbito territorial, reflexionando sobre los aspectos y las líneas de trabajo que debieran ser potenciadas. Tratándose de un problema tan complejo, nuestro único objetivo es el de ofrecer materiales para la discusión que favorezcan el diálogo sobre un aspecto tan importante para la arqueología medieval y postmedieval en nuestro país

Una de las principales características de la arqueología medieval y postmedieval con respecto a otros periodos más antiguos, al margen de la presencia de un mayor número de fuentes indirectas no basadas en la cultura material, es la conservación en mayor cantidad y calidad de restos murarios. Tanto la cercanía cronológica, que ha provocado que los agentes erosivos naturales hayan tenido menos tiempo para actuar, como la creciente extensión en la ocupación del territorio por el hombre respecto a otros periodos, explican el hecho de que las construcciones sean tan numerosas. Igualmente, la frecuente continuidad histórica del poblamiento medieval, así como la continuidad funcional de muchas construcciones, son factores a tener en cuenta.

Estos hechos explican que los avances y desarrollos más importantes en los métodos de estudio arqueológico de las arquitecturas -integradas como un elemento de cultura material perteneciente a la estratificación del yacimiento- se hayan producido en el seno de la arqueología medieval, ya que ha de enfrentarse a las situaciones más complejas. De hecho, esta metodología de estudio es una de las principales aportaciones de la arqueología medieval a la Arqueología en su conjunto.

Desgraciadamente, la juventud de la arqueología medieval y postmedieval en nuestro país como disciplinas y los debates en curso sobre su propio desarrollo, han provocado que aún no se hallan presentado planteamientos más unitarios sobre la aplicación de una arqueología de la arquitectura.

Las publicaciones y trabajos presentes hasta hoy en día se caracterizan por una gran heterogeneidad a la hora de decidir los planteamientos de estudio y análisis de las arquitecturas², lo cual no nos debe extrañar cuando aún existe esa misma variedad con respecto a los métodos de estudio de las propias estratigrafías de los yacimientos.

Así, raramente existen más tendencias para el estudio de las arquitecturas que la del simple soporte de la estratigrafía, el punto de vista estilístico-artístico, o el estructural-funcional. Es difícil encontrar un análisis estratigráfico y arqueográfico de los muramentos que permitan la integración de estos restos de cultura material en el conjunto del yacimiento, ya 
sea explícita o implícitamente.

El término de arqueología de la arquitectura 3 puede resultar muy vago y carente de significado concreto ante su indefinición epistemológica. Evidentemente la estratigrafía muraria, sus métodos y aplicaciones, son bien conocidas por los presentes ${ }^{4}$. Pero, de igual manera que la arqueología prehistórica o clásica no se agota en la excavación y simple recuperación de restos de cultura material, el estudio de los estratos verticales 5 no se acaba en su mera lectura estratigráfica.

La arqueología de la arquitectura no pretende ser una nueva rama de nada, una nueva moda de las que proliferan en los últimos años, ni siquiera un nuevo término para añadir a una lista inútil. Se trata de una manera de gestionar, estudiar y conservar una parte de la Cultura Material de las sociedades pasadas. Las estructuras murarias constituyen, quizás, el patrimonio material heredado más notable y destacado, tanto por su voluminosidad y su significado como por su continuidad funcional. Ante tal riqueza, es evidente que no cabe la definición de procedimientos de análisis monolíticos y lineales, ya que la realidad es compleja y los métodos de estudio deberán adecuarse a las diversas situaciones. Evidentemente, el punto de partida es -como en toda la arqueología científica- el análisis estratigráfico, que permite interpretar en clave histórica los restos materiales.

El edificio arquitectónico, como documento histórico, es de por sí un yacimiento arqueológico. La propia construcción de un muro es un elemento que condiciona y determina la estratificación que se forma a ambos lados del mismo; nunca se formarán los mismos depósitos estratigráficos en el interior y exterior de un determinado ambiente. Además, el propio muro se halla sujeto igualmente a las leyes de estratificación arqueológica6. Así pues, en cualquier construcción se configuran diversas micro-cuencas de sedimentación que se interrelacionan entre sí, y cuya comprensión conjunta es imprescindible para la correcta interpretación del yacimiento.

Hay que añadir que la gran mayoría de las estructuras arquitectónicas -estratos verticales para Harris- no son restos de cultura material abandonados y sin continuidad de uso en el momento presente; son estructuras vivas y dinámicas. Su valor urbanístico, económico y funcional son tan importantes como su papel de documento histórico. Esto condiciona enormemente los métodos de conocimiento que emplea la arqueología de la arquitectura, que deben tender a ser métodos no destructivos. Sólo en determinados casos específicos la labor se convierte en destructiva, equiparable a la excavación arqueológica; es por ejemplo la "excavación" de una estratigrafía de revestimientos, estucos o pavimentos, etc.

Por desgracia, muchas intervenciones arqueológicas resultan bastante dramáticas dentro de la dialéctica arqueología-sociedad, especialmente dentro del casco urbano. Es por eso que la arqueología de la arquitectura presenta tantos paralelos con la arqueología urbana7 y su manera de gestionar el patrimonio.

Por todo ello, y ante lo vasto que es el problema, nos referiremos a continuación al papel de la arqueología de la arquitectura dentro de este marco de relaciones con la sociedad contemporánea, y especialmente a la planificación y ordenación del territorio y a las restauraciones. El interés que puede tener para la investigación pura la arqueología de la arquitectura es también muy grande, pero debe ser valorado en contextos temporales, espaciales y temáticos concretos, que evidentemente sobrepasan los límites del presente trabajo.

\section{LA PLANIFICACIÓN Y ORDENACIÓN DEL TERRITORIO}

Constituye uno de los aspectos más importantes de la relación arqueología-sociedad en el momento presente.

Actualmente la sociedad afronta en un plano material y moral la destrucción de su patrimonio natural y cultural bajo la excusa y las presuntas necesidades que impone el "progreso" y el desarrollo social. La lógica del capitalismo y la especulación privada aniquilan y prostituyen un patrimonio no renovable, hoy amenazado.

Uno de los mecanismos de corrección de estos desequilibrios es la gestión pública del suelo a través de la planificación del territorio. El fin sería el de obtener una simbiosis entre desarrollo capitalista y calidad de vida de la comunidad, entre los intereses 
públicos y privados. En este contexto, el patrimonio cultural -y especialmente el histórico- se ve en cierta manera discriminado. En tanto el patrimonio urbano se incluye dentro de los planes generales de ordenación y otros varios, la Ley del Suelo de 1976 da muy poca importancia a las áreas rurales y a su patrimonio.

En gran parte de los cascos antiguos y centros históricos de nuestras urbes se puede observar cómo, el desplazamiento del centro urbano a áreas de nueva construcción desde el siglo pasado, ha provocado su progresiva degradación y abandono 8 . A pesar de que la planificación busca la rehabilitación de estos cascos históricos, la mano de la especulación privada ha favorecido en muchas ocasiones la degradación del área, esperando la declaración de ruina, el derribo y la posterior de revalorización del suelo.

Si bien se ha producido la progresiva inclusión de historiadores e historiadores del arte en la redacción de estos planes, la intervención del arqueólogo es aún muy reducida. Su participación, generalmente, no tiene lugar más que de forma marginal e indirecta?. Así, se prescribe, en el mejor de los casos, que si se produjesen movimientos de tierras en áreas de riesgo, se realizarán intervenciones arqueológicas planificadas o preventivas 10 . No obstante, en un problema complejo como el de la planificación, es imprescindible abordar los problemas de forma interdisciplinar y global. La planificación, como toda actividad conservadora, es selectiva, y promociona una arquitectura que ha de ser preservada y protegida por el imparable "progreso", frente a otras estructuras de menor valor artístico o urbanístico. El valor de documento histórico debe ser igualmente tenido en cuenta y valorado desde bases arqueológicas; no se trata de defender el conservacionismo a ultranza o incluso la inmunidad del documento histórico, sino de añadir un punto de vista más a una actividad que es compleja y moralmente responsable con las generaciones venideras.

Especialmente la redacción de planes especiales son marcos que debieran de contemplar en su desarrollo actuaciones arqueológicas preventivas II en donde sea necesario, impidiendo tener que llegar a la intervención de urgencia -acelerada y en ocasiones cuando el daño ya ha sido hecho- siguiendo una estrategia de planificación que valore a priori estas exigencias. Igualmente, es necesario la elaboración de mapas de riesgo arqueológico valorando, no sólo las evidencias de superficie y las noticias históricas, sino también analizando críticamente las arquitecturas a través de lecturas estratigráficas de sus muros 12

\section{LA RESTAURACIÓN Y REHABILITA- CIÓN ARQUITECTÓNICA}

Otro aspecto bastante problemático es el de la restauración de monumentos.

Es un hecho notorio que actualmente, y de forma bastante generalizada, la realización de proyectos de restauración y rehabilitación monumental tiende a promover diversas investigaciones que, de forma paralela, permitan conocer el edificio en su integridad (Fig. I). Así, al lado del arquitecto restaurador se forman equipos pluridisciplinares que estudian las diversas problemáticas que presentan las estructuras arquitectónicas' 13 . De forma ocasional, el arqueólogo interviene en esta fase previa a la proyectación, y más raramente durante la ejecución de las obras ${ }^{14}$. Un precedente importante es el que ha supuesto el Plan Nacional de Parques Arqueológicos, en los cuales se han organizado equipos pluridisciplinares para afrontar el análisis global de los yacimientos 15 .

En realidad, y aunque la situación general parece mejorar, este análisis previo preproyectual ha sido definido recientemente de la siguiente manera:

"Se trata de una intervención mínima para la obtención de un conocimiento suficiente del edificio que sirva para la redacción del proyecto básico de rehabilitación .......Económicamente su presupuesto representa, aproximadamente, un 3\% del presupuesto global"16

Evidentemente éstas y otras intervenciones nos hacen reflexionar sobre el verdadero cometido que llegan a asumir estas labores previas, y su verdadera consideración en el proyecto.

Los contrastes entre arqueólogos y arquitectos en este campo de la restauración son contínuos, y en ocasiones la incomprensión mutua impide el diálogo. Es claro que a nadie se le ocurre discutir que 
quien debe elaborar el proyecto de rehabilitación y restauración es el arquitecto, que debe, teniendo en cuenta las exigencias técnico-constructivas e histórico-artísticas, elaborar el plan de actuación. No obstante, es importante que no se produzca una ruptura absoluta entre el nivel de indagación preliminar y el proyectual, convirtiendo el primero en un mero apéndice que justifique la intervención y basta.

La valoración de la intervención, especialmente la intervención destructiva, es un hecho subjetivo desde el punto de vista técnico y cultural. La restauración y la arqueología son disciplinas que no admiten, si no es de forma bastante limitada, la posibilidad de remediar los errores que se producen. Ante la transcendencia que asume la operación, es importante que las labores de indagación preliminar ocupen, en general, un papel importante en la planificación de la intervención, y que exista un diálogo en la fase de proyectación entre los participantes en las indagaciones preproyectuales. Así, el fin a perseguir es que la labor de preproyectación deje de ser pluridisciplinar para pasar a ser interdisciplinar, y que tenga un reflejo en el proyecto.

A su vez, el papel del arqueólogo no puede quedar limitado a unas excavaciones preventivas o de urgencia, en caso de que halla tierras a rebajar o una cimentación que verificar. Es imprescindible un mayor compromiso social de la arqueología en la protección del patrimonio desde todas sus instancias (Universidad, empresas y profesionales, Colegios profesionales, etc.), y también dentro de las intervenciones de rehabilitación y reconstrucción del patrimonio material heredado.

La propia labor restaurativa no es sino una intervención antrópica voluntaria en la estratigrafía vertical de un yacimiento, con aportación y extracción de materiales; esto es, formando Unidades Estratigráficas Murarias (UEM) positivas e interfases de destrucción (UEM negativas). Así pues, la lectura arqueológica de un edificio es una labor mucho más global y articulada que la realización de un sondeo de forma ocasional.

La inclusión del análisis estratigráfico global del edificio en las labores de indagación preventiva, se convierte en un deber y un derecho del arqueólogo. Este análisis permite precisar la secuencia sincró- nica de construcciones y reconstrucciones del edificio, verdadero armazón para la comprensión global del edificio.

Pero el análisis estratigráfico no debiera pararse en el mero registro del estado de cosas anterior a su intervención y su interpretación; también durante las intervenciones se producen destrucciones y se obtienen nuevas informaciones a través de un proceso que nos recuerda por su paralelismo la excavación arqueológica. Así, el levantamiento de cargas y revestimientos pone al descubierto estructuras murarias que pueden contener una gran información estratigráfica, o igualmente se produce la destrucción de material constructivo o su sustitución, que también puede estar cargado de información (se piense en piezas de madera de interés para la dendrocronología, o de piezas líticas, argamasas, etc.).

Igualmente, tras la intervención nos encontramos ante una nueva configuración y un nuevo equilibrio estratigráfico que hay que documentar, de manera que sea contrastable la realidad estratigráfica inicial y final.

Evidentemente este planteamiento teórico se debe ajustar a la realidad existente, a la profundidad de la intervención, etc. Como señala R. Francovich, la profundidad del conocimiento debe ser proporcional al grado de la intervención ${ }^{17}$.

Así pues, el conocimiento estratigráfico de los avatares del edificio y su interpretación es una vía irrenunciable para llegar a comprenderlo en su integridad, y que debiera integrarse en los análisis preliminares de las restauraciones. La documentación de las evidencias materiales es un aspecto muy importante de la labor del arqueólogo, pero la documentación no se justifica en sí misma, debe tener una función y jugar su papel en el propio proyecto de restauración y rehabilitación.

Evidentemente para afrontar estos y otros fines que la arqueología de la arquitectura debe proponerse, es tarea indispensable que se dote de unos instrumentos de trabajo. En primer lugar, refiriéndose a la lectura estratigráfica, es necesario que se adopte un sistema de registro y documentación flexible pero uniformado, que permita el intercambio de información entre los diversos miembros del 
equipo de trabajo y con otros profesionales. La falta de diálogo -a la que ya antes nos referíamos- en la fase operativa de la proyectación, no puede ser oscurecida aún más por sistemas particulares y restringidos de registro y exposición de datos. Siguiendo la lógica estratigráfica, es de vital importancia la elaboración de una ficha modelo de Unidad Estratigráfica Muraria que sirva de instrumento de trabajo y de comunicación, así como otras fichas y modelos de documentación rápida que sean adecuados a nuestros fines. La diversidad técnica, litológica y cultural plantea serios problemas a la hora de buscar un modelo flexible y que pueda ser aplicado de forma universal. Sólo a base de experimentar diversos modelos en diversos ámbitos espaciales y temporales variados se podrá pensar en elaborar procedimientos de mayor ámbito.

\section{INDICADORES CRONOLÓGICOS}

Además de la lectura estratigráfica, es imprescindible que el arqueólogo se dote de una serie de instrumentos críticos de comprensión y datación de la cultura material para intervenir en trabajos de planificación y restauración. Igual que hoy la Arqueología Medieval en España cuenta entre sus principales líneas de investigación y de trabajo la seriación de cerámica y otros restos de cultura material, elaborando crono-tipologías para poder hacer historia, la arqueología de la arquitectura debe desarrollar sus propios indicadores cronológicos (Fig. 2) que le permita poseer herramientas para la comprensión de los elementos arquitectónicos 18 .

Estos indicadores cronológicos son, potencialmente, muy variados y de naturaleza muy diversa. En la práctica, sólo son aplicables algunos de ellos, dependiendo del tipo de restos arquitectónicos presentes y del desarrollo de la investigación. Lo más normal es que para llegar a la comprensión de un conjunto pluriestratificado, sea necesario el empleo de varios de ellos, de forma interrelacionada.

A la hora de elegir unos u otros, es necesario tener en cuenta los siguientes aspectos:

I) de un lugar está el coste, que en casos de análisis de laboratorio de una cierta complejidad pueden ser bastante altos.
2) otro aspecto importante es la precisión cronológica del método, que no siempre esta en relación o en proporción con su coste.

3) la rapidez es otra variable importante, especialmente en el caso de análisis de laboratorio o en el de la arqueología involuntaria o de gestión.

4) dentro del contexto social en el que se tiene que desarrollar la arqueología de la arquitectura, otro elemento a tener en cuenta -como ya hemos señalado- es el carácter destructivo o no del análisis destinado a establecer una cronología. El hecho de que no sea destructivo permite que el análisis sea revisable en todo momento, lo cual resulta extremadamente importante en una ciencia acostumbrada a tener una sola oportunidad a la hora de recoger y leer sus datos.

5) por último, otro aspecto importante es el ámbito de aplicación de cada método. En tanto los métodos de datación basados en el aporte de las ciencias naturales (como la termoluminiscencia, el radiocarbono, etc.), tienen una aplicación universal, las tipologías de técnicas constructivas y morfologías arquitectónicas están supeditadas a la existencia de un conocimiento local de las construcciones en el tiempo, con el fin de poder establecer paralelos.

Como ha señalado Mannonil9, la distinción fundamental entre los diversos métodos de datación es su división según su campo de trabajo; las dataciones DIRECTAS se basan en elementos o características presentes en el registro material, en tanto que las dataciones INDIRECTAS parten de referencias externas a estos mismos restos materiales.

Comenzando por las fuentes indirectas, habría que hacer una primera distinción entre la documentación oral referida a estas construcciones, la documentación escrita (narraciones, libros de fábrica, etc.), así como la documentación gráfica (cartográfica, iconográica, fotográfica, etc.). A pesar de ser muy abundantes, las fuentes indirectas presentan bastantes límites, ya que en ocasiones resulta bastante problemático establecer una relación precisa entre la noticia y el elemento material.

Por su parte, las fuentes directas son muy numerosas y variadas. Dentro de ellas hay que establecer una primera división entre aquellas basadas 
en análisis arqueográficos y arqueométricos. En tanto los primeros se refieren a las observaciones, deducciones y documentación descriptiva de las evidencias materiales, los análisis arqueométricos se corresponden a los datos que son medibles, y a los estudios científicos (entendidos como ciencias naturales) de los restos materiales ${ }^{20}$.

Así pues, dentro de los análisis arqueométricos hay que distinguir de una parte la mensiocronología, esto es, el estudio de las variaciones dimensionales de materiales o piezas de cultura material con un significado cronológico. Como veremos más adelante, es aplicable especialmente a materiales constructivos o a elementos arquitectónicos. Son análisis no destructivos y que llegan a alcanzar una gran precisión. Igualmente análisis arqueométricos son los aportes de las ciencias naturales, impropiamente denominadas ciencias auxiliares de la arqueología 21. Generalmente son análisis destructivos que se basan en diversas técnicas desarrolladas por la geocronología que permiten datar de forma absoluta restos arqueológicos; así por ejemplo la dendrocronología (en el caso de materiales leñosos), el radiocarbono (en el caso de materia orgánica), la termoluminiscencia (en el caso de cerámica) o el arqueomagnetismo (en el caso de hornos u hogares). Igualmente otros análisis químicos, físicos y mineralógicos permiten obtener otras informaciones que pueden llegar a tener un significado cronológico22 (la determinación y caracterización de componentes, la proveniencia de materiales, análisis tecnológicos, la degradación de materiales, etc.).

Los análisis arqueográficos, en cambio, pueden dividirse según su incidencia en destructivos y no destructivos.

Evidentemente los análisis destructivos son fundamentalmente las lecturas estratigráficas; esto es, las excavaciones. En este caso nos referimos tanto a la excavación de estratos horizontales, o sea, a la excavación en el sentido tradicional, con sus ya consabidos efectos destructivos, como a la remoción de estratos verticales (como el caso de la excavación de una estratigrafía de cargas, de morteros, registros de paramentos de todo tipo, etc. ${ }^{23}$.

En cambio, los análisis no destructivos, y por tanto de gran interés para la práctica de la arqueología de la arquitectura, son muy variados:
- La epigrafía resulta de gran importancia por su precisión cronológica. Su integración, en bastantes ocasiones, en la estratigrafía vertical facilita el paso de las cronologías relativas a absolutas.

- Prospecciones, que permiten conocer restos arquitectónicos ocultos. Hay que distinguir las prospecciones realizadas en suelos con el fin de conocer los restos enterrados (eléctricas, electromagnéticas, etc.). y las realizadas en estructuras en alzado, como pueden ser la termografía, los ultrasonidos, etc.

- Estratigrafía horizontal, es decir, la estratigrafía muraria.

- La elaboración de tipologías²4, tanto de técnicas constructivas como de morfologías arquitectónicas, con un significado cronológico (es decir, cronotipologías). Así por ejemplo tipologías de capiteles, elementos defensivos, aparejos, coberturas, elementos o esquemas decorativos, distribución de fachadas, tipologías de casas, etc.

- La presencia de cerámicas u otros restos de cultura material murados en los edificios, en sus rellenos, presentes en su fosa de fundación, sobre bóvedas y cúpulas, etc 25 .

Así pues, son muchos los métodos de posible utilización, y también muchos los criterios a considerar a la hora de decidir el empleo de uno u otro. Si bien los análisis de laboratorio son muy precisos, su coste es muy alto y sus resultados se pueden hacer esperar bastantes meses. En cambio, el empleo de las crono-tipologías, una vez que se han establecido las bases de referencia, es un método rápido, de precisión variable (según como se ha conducido el análisis preliminar) y de costes bajos. Por tanto, sólo dentro de una estrategia de trabajo global es posible valorar el problema concreto.

\section{LINEAS DE INVESTIGACIÓN}

Tal como acabamos de ver, siendo muchos los métodos de datación, la experiencia demuestra que variables como el coste, la rapidez, la precisión son de gran importancia a la hora de operar en cualquier intervención arqueológica. Si bien potencialmente para datar cualquier estrato (tanto horizontal como vertical) son también muchos los métodos y técnicas de posible utilización, no pode- 
mos hacer análisis de radiocarbono en cada ocasión, y por ello el método tipológico comparativo es el más empleado por la arqueología. Así pues, debido a su gran interés, creemos que el desarrollo de cronotipologías arquitectónicas es una línea de investigación que debe ser potenciada por los diversos grupos de trabajo de arqueología medieval.

La elaboración de estas cronotipologías arquitectónicas debe partir de una comprensión global de todos los elementos que componen el edificio, superando el mero análisis superficial. Para obtener estos fines, es imprescindible el estudio de los diversos materiales, técnicas y elementos constructivos, y su tipologización con carácter sincrónico.

Con todo, son muchos y muy complejos los factores que condicionan y determinan cuáles son las técnicas y materiales de construcción empleados; desde los mismos condicionamientos físicos hasta los humanos. Así, entre los primeros, la topografía impone determinadas soluciones arquitectónicas, al igual que la litología determina el material a emplear; de otro lado, las tradiciones y conocimientos técnicos, los condicionamientos históricos, culturales y socioeconómicos influyen igualmente sobre las edificaciones.

Ante estas circunstancias, es imprescindible que los estudios y clasificaciones arquitectónicas partan de microanálisis de áreas locales que presenten características geográficas e históricas comunes, sin tratar de trasladar las conclusiones obtenidas en unas zonas a otras, culturalmente distintas o geograficamente alejadas.

En nuestro país se han realizado ya bastantes clasificaciones y tipologías de material arquitectónico, especialmente referidas a la arquitectura monumental o "señorial", y generalmente ocupándose de problemas bastante concretos. Tal es el caso del estudio del arco de herradura26 o de las tipologías de capiteles27. Pero a la hora de afrontar las edificaciones de un ámbito local sin prejuicios cronológicos o funcionales, es muy difícil de encontrar elementos de confrontación susceptibles de clasificación. Por ello, el estudio de las APERTURAS28 (ventanas y puertas) aparece como el elemento cronológico de mayor interés a la hora de tipologizar, por la universalidad de las mismas así como por su característica de variar siguiendo modas y tradiciones. Como ha señalado Isabella Ferrando ${ }^{29}$, siendo el medio de relación entre el interior y el exterior de la casa, a través de su morfología, dimensiones y decoración se convierte en un instrumento de transmisión del status symbol del poseedor del edificio. En palabras de Mannoni, son los ojos y la boca de las fachadas 30 .

Antes de continuar, es importante tener en cuenta una primera premisa metodológica que condicionará nuestros análisis: la historia de la producción arquitectónica, al menos en el período preindustrial, puede ser dividida en dos grandes líneas, aún cuando en ocasiones la separación no sea tan neta 31 :

-Arquitectura popular o "menor", realizada con materiales locales, con mano de obra local, muchas veces sin especializar. Usa formas y técnicas muy estandarizadas y repetitivas, con soluciones arquitectónicas simples y continuistas. Domina un sentido práctico y utilitarista.

Es la producción más numerosa, pero también la más frágil y la de peor conservación. Generalmente es estudiada por etnólogos, que suelen prescindir de su carácter evolutivo y presentan modelos acabados de tipos arquitectónicos, de difícil confrontación con la realidad.

-Arquitectura monumental o "señorial", realizada con materiales seleccionados, mano de obra especializada, con proyectos y soluciones arquitectónicas originales e innovativas. Al lado del carácter práctico, domina una función simbólica o carga ideológica muy fuerte. Son iglesias, palacios y otras edificaciones construídas con la intención de durar, y en las que, aunque existan formas y estilos comunes (hablamos de románico o gótico, aunque a veces se pierda su significado), no existe una estandarización de la producción, y la personalidad de cada uno de estos edificios es muy marcada. Con respecto a los anteriores, se cuenta con un mayor número de fuentes de datación (documentación escrita, epigráfica, etc.). Son objeto de estudio por parte de los historiadores del arte, que no obstante realizan un estudio superficial, sin profundizar excesivamente en aspectos técnicos, metrológicos, etc., y, en ocasiones, su contexto y significado histórico. 
A la hora de estudiar las aperturas en ambos casos, vemos que, en su mayoría, la arquitectura señorial presenta puertas y ventanas que morfológicamente no tienen paralelos, siendo casos únicos que no encuentran relación ni con otros edificios de su género, ni mucho menos con la arquitectura popular. A pesar de que en muchas ocasiones son mucho más fáciles de datar -no sólo por el interés por su estudio como arquitectura "de estilo", sino también por la mayor riqueza de fuentes indirectas y directas (documentación escrita y epigráfica)- su interés para comprender las tendencias constructivas globales de un grupo humano es muy bajo32. Su funcionalidad se redimensiona dentro de un estudio de la arquitectura canónica a nivel regional (como realiza la historia del arte), pero los ritmos de la arquitectura popular son muy distintos.

Incluso, en ocasiones, intervienen redes de mayor alcance, registrándose la importación de puertas ya elaboradas. Cabe destacar, por ejemplo, una puerta fabricada en Génova en el año 1609 , con evidentes paralelos en el palacio Ducal de aquella ciudad, destinada al palacio que el embajador español en Génova poseía cerca de Valencia33

Con todo, el problema debe afrontarse desde una globalidad de la producción arquitectónica, pues en ocasiones sí hemos podido observar cómo la arquitectura señorial llega a influir, aún de manera indirecta, en la arquitectura popular (especialmente la urbana); a pesar de precisar de soluciones arquitectónicas distintas, se reinterpretan -a nivel muy elemental- parte del contenido formal.

Sintetizando, si bien es de mayor dificultad su conocimiento (incluido el menor interés que despierta entre los estudiosos), es la arquitectura popular o "menor" la de mayor interés a la hora de tipologizar, pues se tratan de producciones en serie sujetas al mercado y que mejor permiten comprender un contexto pluriestratificado urbano o el anonimato de la arquitectura rural.

La elaboración de estas tipologías precisa en la fase inicial de un soporte de dataciones que no dependan de variaciones regionales, y que garanticen dataciones precisas. Así, es necesario recurrir a otros indicadores cronológicos, y especialmente a las fuentes indirectas (si es posible atribuir con seguridad la datación a la evidencia material), y la inscrip- ción de fechas en las puertas. En concreto, las fechas incisas en claves y arquitrabes de puertas en posición primaria, son óptimas referencias cronológicas por su gran fiabilidad. Esto explica que en ocasiones la elaboración de las tipologías puede ser un proceso bastante largo, debido a la necesidad de emplear un gran conjunto de indicadores cronológicos para obtener dataciones precisas de las puertas en un número suficientemente representativo. Es también importante considerar que, aumentando la muestra, se proporcionará una mayor precisión y validez a la tipología. Ante estas exigencias se impone una estrategia de documentación de las evidencias arquitectónicas sobre el territorio de forma continuativa, donde el aspecto cognoscitivo y el conservativo van íntimamente ligados.

A continuación queremos exponer un trabajo que, encontrándose aún en curso de realización, y por tanto de conclusiones limitadas, ilustra la problemática. Se trata de la tipología de puertas de la ciudad de Oviedo (Fig. 3 ), que se incluye en un proyecto más amplio de elaboración de indicadores cronológicos que sirvan para la comprensión de las edificaciones de la capital asturiana.

Hay que partir, a la hora de estudiar este caso concreto, de una censura importante; la que supuso el incendio que devastó la ciudad en el año |52 |34. El Padre Carballo en el siglo XVII nos describía de esta manera los efectos del mismo: "toda la ciudad se abrasó dentro de los muros, si no fue la Santa Iglesia que quedó libre en medio del incendio, aunque el maderage y andamios de una torre, que se iba haciendo, se quemó también. Quedan algunas casas, aunque pocas..."35. Nuestros estudios aún no nos han permitido identificar construcciones anteriores a la fatídica fecha, más que las antiguas construcciones prerrománicas, pocas trazas eclesiásticas románicas, así como la catedral gótica36. Cabe añadir, por último, un palacio (Palacio de la Rúa) que se ha venido atribuyendo tradicionalmente a fines del siglo XV37. Como vemos, son todos edificios referibles a la arquitectura "monumental" o "señorial", y que por tanto tienen un interés relativo para conocer la arquitectura del momento.

Hay que esperar hasta el siglo XVIII para poder documentar, en el momento actual de nuestras investigaciones, ejemplos de arquitectura "menor" datada con seguridad a partir de fuentes directas 
(inscripciones en los arquitrabes o fachadas de los edificios). No obstante, aún se trata de una investigación en curso, y esperamos encontrar evidencias más antiguas.

La línea de trabajo que se ha seguido es la de individualizar puertas con dataciones precisas a partir de fuentes indirectas y directas. Posteriormente se ha pasado al análisis de cada caso de forma pormenorizada, contemplando tres aspectos principales: el morfológico, el técnico y el métrico. Así, y según una ficha modelo de recogida de datos (Fig. 4), hemos estudiado más de medio centenar de aperturas con datación precisa entre el siglo XV y las dos primeras décadas del presente siglo, documentando sus diversos aspectos y atributos con el fin de dotarlos de un significado cronológico. Aunque actualmente solo unos pocos de estos atributos, generalmente los métricos, pueden dar precisiones cronológicas, aumentando la muestra esperamos conseguir otros resultados.

El material constructivo es bastante homogéneo, predominantemente lítico, con ausencia casi total del ladrillo. La piedra predominante es la arenisca, que constituye la base litológica de gran parte de la urbe, habiendo canteras documentadas desde al menos el siglo IX38. La presencia en los alrededores de material calizo tampoco provoca problemas de aprovisionamiento de cal para las argamasas. Así pues, esta homogeneidad litológica y humana que constituye una ciudad que se desarrolla ininterrumpidamente del siglo VIII a la actualidad, constituye un ejemplo óptimo para la realización de un estudio territorial.

Con todo, las conclusiones más interesantes a las que llegamos actualmente son las referidas a las medidas de las puertas 39 . Hemos tenido en cuenta especialmente las medidas de la altura y la anchura de los vanos, así como la proporción existente entre ambos valores. Este último valor tiene cierta importancia, ya que está condicionado por la morfología y funcionalidad de la puerta, así como por la composición de las fachadas. En otras ocasiones las variaciones de estos valores se han demostrado como un instrumento válido de discriminación cronológica, precisando las dataciones más allá de la mera clasificación formal40.

En el caso de Oviedo, estos valores permiten observar una tendencia al crecimiento desde el I al 2 (Fig. 5), si bien el análisis no está exento de problemas; de un lado el dominio de la arquitectura señorial en los primeros siglos del período analizado, y de arquitectura popular en los últimos, lo que provoca desigualdades; de otro lado una bondad de ajuste de los valores a la tendencia señalada no muy alto (valor del índice de regresión del 0,57).

Con todo, la acumulación progresiva de elementos con significado cronológico permitirá un mayor acercamiento a la realidad.

Pero volviendo a los análisis métricos, una segunda línea de trabajo que creemos que deba desarrollarse es el estudio de los materiales de construcción, y en particular el análisis de las medidas de los ladrillos ${ }^{4}$. En el sector noroeste de la península, debido a la abundancia de la piedra y la ausencia de tradición cultural, el ladrillo no se emplea más que muy esporádicamente en el periodo preindustria|42. No obstante, es de gran interés su aplicación para otras regiones donde la litología y las condiciones constructivas son más favorables. Por ejemplo, la casa entramada con muros de madera y relleno de ladrillo (Sierra de Gredos, Guadarrama, Sistema Ibérico o País Vasco), o las de ladrillo de la Meseta, Ebro o Andalucía, etc ${ }^{43}$.

Algún trabajo sobre las medidas de los ladrillos y su significado cronológico, a decir verdad, ya ha sido realizado en nuestro país, si bien referido al periodo romano y en un ámbito espacial reducido 44 .

Lo que parece claro, es que tras la ruptura del mundo clásico, de igual manera que es observable la ruptura de los mercados de producción de cerámica, lo mismo debió ocurrir con la producción de ladrillos, producto que debió de hacerse bastante extraño en la arquitectura altomedieval.

Por ejemplo, reaparece el empleo del ladrillo en la arquitectura asturiana ya desde los siglos VIII y IX, donde, si bien se emplean módulos de tradición romana en la construcción de los edificios ${ }^{45}$, medidas realizadas en los ladrillos empleados en la construcción de las iglesias de este periodo indican que se han abandonado los módulos romanos, síntoma de esta ruptura. Otro aspecto importante del ladrillo en este momento es el carácter de artículo de lujo que adquiere, reservándose a aplicaciones fun- 
cionales muy específicas (arcos), en tanto las edificaciones se construyen en fábrica.

No obstante, aún no conocemos prácticamente nada sobre la producción del ladrillo en el medievo, e incluso en fechas posteriores; su historia está aún por hacer.

Hay que destacar la importancia que para el arqueólogo puede llegar a tener el conocimiento de la producción de ladrillos y tejas, pues siendo un elemento material y de uso muy extendido, se convierte en un magnífico instrumento para el conocimiento del comercio local y la economía de un territorio en época preindustrial. La localización de los centros productivos, la caracterización litológica y técnica de las diversas producciones y el estudio de su circulación se convierten así en una importante llave de lectura, incluso en economías pobres ${ }^{46}$.

Como ya es bien conocido, el interés del estudio dimensional del ladrillo y su valor como indicador cronológico radica en que, tratándose de un bien sujeto al mercado y realizándose su adquisición en orden numérico, se ha observado como existe la tendencia a la disminución de las medidas de los ladrillos de forma lineal y progresiva. La explicación dada a esta disminución sería la del interés del productor por, reduciendo las dimensiones del ladrillo, obtener en cada hornada mayor cantidad de unidades, y menor coste de elaboración de cada ladrillo. Igualmente, estando sujeto a las tendencias de mercado, las variaciones monetarias e inflacionistas tienen su influencia ${ }^{47}$. Cabe señalar como importante excepción el modélico estudio de R. Corsi en la ciudad de Siena ${ }^{48}$, donde se produce un aumento.

Partiendo de esta premisa teórica, conociendo las tendencias y ritmos de decrecimiento (o crecimiento en su caso) de estos ladrillos a partir de la observación de contextos datados, podremos estimar a través de procedimientos estadísticos la datación de un conjunto homogéneo de ladrillos no datados a partir de sus dimensiones.

Evidentemente, estos estudios solo se pueden aplicar en lugares donde el ladrillo se emplea abundantemente como material de construcción en el tiempo, y donde en base a otros procedimientos se han llegado a datar con precisión cortinas murarias en ladrillo; esto explica cúanto sea importante la planificación de una estrategia de investigación que contemple de la forma más amplia posible la realidad arquitectónica.

Además, se deben tener en cuenta otras circunstancias, según cúal sea el ámbito de aplicación de estos estudios:

I) Ambito urbano. Es el lugar donde mayoritariamente ha estado aplicado hasta ahora el estudio de las variaciones dimensionales del ladrillo. Favorecido por la presencia de un mercado unificado, más continuo y de un mayor consumo, se dan las condiciones óptimas para su aplicación, siempre que se encuentre en un marco geográfico adecuado.

La riqueza y variedad morfológica de la arquitectura urbana requiere, en ocasiones, de ladrillos con distinta funcionalidad y características, y también con diversidad de medidas, por lo que la convivencia de varios "tipos" de ladrillos con diversidad de medidas puede provocar problemas.

La riqueza de la arquitectura monumental y de fuentes indirectas de datación permite datar con mayor facilidad los conjuntos de ladrillos, abriendo la puerta a la datación de la arquitectura popular que emplee estos materiales constructivos.

2)Ambito rural. El ladrillo como material constructivo suele convertirse en un verdadero lujo49. La presencia de piedra, o incluso de materiales más pobres, reduce el uso del ladrillo a funciones muy específicas. En otros casos, el ladrillo aparece como único material.

Los mercados, como sucede en el campo preindustrial, están muy partidos y fragmentados. Ante estas circunstancias, el consumo es menor y el reutilizo mayor. En casos de condiciones favorables para la producción (presencia de agua, leña y arcillas adecuadas), se encuentran múltiples centros productivos, de ámbito muy local y de uso intermitente. Así, los análisis métricos llegan a tener una aplicación muy reducida a un pueblo o un conjunto pequeño de ellos 50 .

En el caso de dificultades en el aprovisionamien- 
to de materias primas, la situación se hace aún más compleja, cuestionando la factibilidad de estos estudios.

Por último, otras líneas que creemos deban potenciarse, de especial interés para el desarrollo de la arqueología de la arquitectura, son los aportes de las ciencias naturales. Cabe destacar, entre otras contribuciones también importantes, la dendrocronología 5 !.

La madera es un material de construcción empleado de forma muy masiva hasta épocas muy recientes en amplias zonas de la península. Se ha usado combinado con la piedra, el barro, o incluso se ha construido solo con madera, como en el caso de la txabola vasca. La datación de los materiales leñosos a partir de la cuenta de sus anillos de crecimiento anual constituye, potencialmente, un eficaz método de datación. Pero es importante que los grupos de investigación se preocupen en recuperar, documentar y muestrear maderas datadas en contextos estratigráficos, tanto en alzado como enterrados, con el fin de proceder a la construcción de curvas de referencia regional para las distintas especies de árboles empleados en la construcción. Igualmente es imprescindible que existan laboratorios de arqueometría que lleven a cabo la recogida de muestras, su estudio y las dataciones subsiguientes, ofreciendo un servicio que permita que la datación dendrocronológica se convierta en práctica habitual.

Con todo, solamente partiendo del análisis razonado de los diversos materiales y técnicas constructivas, de las tradiciones culturales, etc., es posible establecer cuáles son los indicadores cronológicos más adecuados o con mayor funcionalidad a la hora de ser aplicados y desarrollar otros nuevos a partir de las problemáticas existentes. Así por ejemplo, las numerosísimas construcciones en barro crudo secado al sol que se extienden por amplias zonas de los valles del Duero y Ebro, la Meseta, las huertas levantinas, etc., aparecen técnicamente muy condicionadas por el material de construcción, lo que provoca que el problema deba afrontarse de forma particular52. Idéntica situación sería la del hábitat troglodítico 53.

\section{CONCLUSIONES}

Así pues, concluyendo, creemos que la primera labor a la que debe enfrentarse la arqueología de la arquitectura es la de elaborar sus llaves de conocimiento sincrónico a base de la asunción de una estrategia de investigación y recogida de datos. Esta estrategia debiera basarse en una documentación exhaustiva que, de forma global e indiscriminada, analice las arquitecturas en ámbitos locales homogéneos. Global, considerando todas las variantes arquitectónicas, tanto las conservadas en alzado como las que vienen puestas a la luz por las excavaciones arqueológicas; de forma indiscrimanda, sin partir de prejuicios cronológicos, buscando comprender la problemática en su conjunto. En centros pluriestratificados con continuidad de uso hasta el presente -como son los centros urbanos- donde la construcción, ampliación y rehabilitación han sido práctica común hasta nuestros días, resulta difícil llegar a conocer la arquitectura medieval sin conocer la postmedieval54.

Una vez que se conozcan las realidades locales, será posible inductivamente contrastar los datos e intentar establecer las tendencias regionales, encuadrando los problemas en contextos más amplios.

En la actualidad, los estudios que mueven al arqueólogo hacia la arquitectura se ven mediatizados generalmente por una labor de indagación preproyectual en relación con actividades de rehabilitación o restauración monumental. Esto provoca el análisis selectivo y el olvido de la arquitectura "menor". Ante todas estas necesidades, solamente la programación y planificación de la investigación nos permitirá profundizar en la exploración de una cultura material aún por descubrir55.

\section{NOTAS}

I Ver por ejemplo BLANCO 1992, pág.436

2 Ver las Actas de los Congresos de Arqueología Medieval (Huesca 1985, Madrid 1987, Oviedo 1989), o los números del Boletín de Arqueología Medieval

3 El término es el empleado por el Notiziario di Archeologia Medievale, que le dedica una sección desde su número 54 (noviembre 1990). 
4 Basta destacar entre otras aportaciones BROGIOLO 1988, PARENTI 1988a, PARENTI 1988b, BOLDRINIPARENTI 1991. Hay que señalar como trabajos pioneros en nuestro país los de Caballero Zoreda. CABALLERO ZOREDA-LATORRE MACARRON 1980

5 HARRIS 1991, pág. 75 y ss.

6 HARRIS | 99|, pág. 5 | y ss.

7 VALDÉS 1989, RIBERA 1989

8 CAPEL 1975

9 Las recomendaciones del Consejo de Europa sobre Patromonio Urbano y Rural, aprobadas el 13 de junio de 1989, sugieren en su apartado III: "Adoptar las medidas jurídicas y de organización administrativas necesarias a la incorporación sistemática de los datos arqueológicos en el proceso de las operaciones urbanísticas en el ámbito urbano y rural". En esta misma recomendación se precisa la necesidad de la "participación de los arqueólogos a lo largo de las diversas fases del proceso de urbanismo y de ordenación territorial con el fin de recoger su punto de vista en las operaciones llevadas a cabo".

10 Por ejemplo en el caso del Principado de Asturias, las Directrices Regionales de Ordenación del Territorio del 24 enero 1991, su directriz I I ${ }^{\text {a }}$ :Criterios para el tratamiento urbanístico del Patrimonio monumental, histórico, artístico, arqueológico, etnológico e industrial".

II Sobre el concepto de arqueología preventiva GARDINI-MILANESE 1979, pág. 130; concepto similar es el de arqueología planificada de RIBERA 1989, pág. 26

12 Un caso de aplicación de la arqueología en la planificación urbana, y de la arqueología de la arquitectura en concreto ZIGRINO 1988

\section{GARCÍA CUETOS 1987}

14 Ver por ejemplo las intervenciones recogidas en el segundo volumen Excavaciones Arqueológicas en Asturias (1987-1990)

15 LATORRE GONZÁLEZ-MORO 1988

16 PLEITE MARTIN 199I, págs. 102-3

17 FRANCOVICH 1988, pág.26
18 MANNONI 1984a plantea brillantemente las diversas fuentes y métodos de datación de las arquitecturas, recogidas posteriormente en PARENTI 1988b

19 Ver nota anterior.

20 Sobre el concepto de Arqueometría MANNONI 199

2I Ver nota anterior

22 MANNONI 1984b, BOATO-GROTTIN 1992, pág. 13

23 SOUTO LASALA 1986

24 Entre otras aportaciones: EWERT-CRESSIER-ZOZAYA 1990, HERRERA MENEDEZ-TAPIA SUAREZVILLAMERIEL FERNANDEZ 1985, MIYARES FERNANDEZ 1986, CABALLERO ZOREDA 1977-1978

25 BASSEGODA NONNELL 1983, PLEITE MARTIN 199| pág. 13

${ }^{26}$ CABALLERO ZOREDA $1977-78$

27 EWERT-CRESSIER-ZOZAYA 1990, HERRERA MENEDEZ-TAPIA SUAREZ-VILLAMERIEL FERNÁNDEZ 1985

28 Ver QUIRÓS CASTILLO 1992a, FERRANDO-MANNONI-PAGELLAI989, FERRANDO CABONA-CRUSI 1980, MANNONI 1980, FERRANDO CABONACRUSI 1979, FERRANDO CABONA-GARDINI-MANNONI 1978

29 FERRANDO-MANNONI-PAGELLA 1989, pág. 652

30 Ver nota anterior.

31 POUNDS 1992, págs.418-23

32 FERRANDO-MANNONI-PAGELLA 1989, pág. 650

33 BOATO-GROTTIN 1992, págs. 60-I, figs.50- I

34 CANELLA Y SECADES 1888, pág. 53

35 CARVALLO 1695, pág.46 |

36 Ver descripciones y referencias en $C O B O$ ARIASCORES RAMBAUD-ZARRACINA VALCARCE 1990 
37 URIA RIU 1967, págs. 22 y ss.

38 URIA RIU 1967, pág.5

39 Referido al análisis matemático en arqueología ORTON 1988, SHENNAN 1992

40 Ver como ejemplo QUIROS CASTILLO 1992a, págs. 732 y ss.

4I MANNONI-MILANESE 1988, CORSI 1988-89, CORSI 1991, QUIRÓS CASTILLO 1992b

$42 \mathrm{Su}$ empleo en el noroeste peninsular es muy escaso. LLANO 1989; GRAÑA-LÓPEZ 1981

43 SANTANA EZKERRA 1989, BOLOS Y CAPDEVILA 1987

44 ROLDÁN GÓMEZ 1987

45 ARIAS PARAMO 1992

46 QUIRÓS CASTILLO $1992 b$

47 FOSSATI 1985, MANNONI-MILANESE 1988

48 CORSI 1988-89, CORSI I99|

49 "Los ladrillos cocidos (..) han sido durante mucho tiempo materiales costosos, lo que explica que normalmente estén reservados a las construcciones urbanas." LEROI-GOURHAN 1989, tomo II, págs. 232-3

50 QUIRÓS CASTILLO 1992b

5 I CASTELLETI 1988

52 SALAS 199|; GUINEAI99|, TORRO-IVARS 1992, pág.474-5

\section{BERTRAND 1986}

54 Un caso interesante de análisis arqueológico de edificios postmedievales es el de COUTTS 1977

55 Un ejemplo de planificación de la investigación lo constituye la estrategia de Arqueología Global; MILANESE-QUIRÓS 1993, MANNONI-CABONA-FERRANDO 1988

\section{BIBLIOGRAFÍA}

AA.W., 1991, Jomadas sobre Restauración y Conservación de Monumentos, Madrid 24-25 Abril 1989, Ministerio de Cultura

ARIAS PARAMO, L., 1992, "Geometría y prospección en la Arquitectura Prerrománica Asturiana", III Congreso de Arqueología Medieval Española, págs. 27-37, tomo II Comunicaciones, Oviedo

BASSEGODA NONELL, J., 1983, La cerámica popular en la arquitectura gótica, Barcelona

BERTRAND, M., 1986, "El hábitat troglodítico antiguo de la Hoya de Guadix (Granada)", págs. 263-83 en Arqueología Espacial. Coloquio sobre el microespacio-4, vol. I0, Teruel

BLANCO, J.F., I992, "El circuito amurallado de Coca", III Congreso de Arqueología Medieval Española, págs. 433-38, tomo II Comunicaciones, Oviedo

BOATO, A., GROTTIN, F. V. (a cura di), 1992, Archeologia della città. Palazzo Ducale, SAGEP, Genova

BOLDRINI, E., PARENTI, R. (a cura di), I99I, Santa Maria della Scala. Archeologia e edilizia sulla piazza dello Spedale, Florencia

BOLOS Y CAPDEVILA, M., 1987, "El poblamiento rural", págs. 269-9I en Geografía de España, dirigida por TERÁN, SOLÉ SABARIS, VILÀ VALENTÍ, Barcelona

BROGIOLO, G.P., 1988, Archeologia dell'edilizia storica, Como, New Press

CABALLERO ZOREDA, L., 1977-78, "La 'forma herradura' hasta el siglo VIl y los arcos de herradura en la iglesia visigoda de Santa María de Melque", Archivo Español de Arqueología 50-5I, págs. 323 y ss.

CABALLERO ZOREDA, L., LATORRE MACARRÓN, J.L., 1980, "La iglesia y monasterio visigodos de Santa Maria de Melque (Toledo). Arqueología y arquitectura", Excavaciones Arqueológicas en España 109, Madrid

CANELLA Y SECADES, F., I888, Oviedo. Guía, Oviedo

CAPEL, H., 1975, Capitalismo y morfología urbana en España, Barcelona

CASTELLETTI, L., 1988, "Dendrocronología", págs. 42I454, en Archeologia e restauro dei monumenti 
CARVALLO, L. A., 1695, Antigüedades y cosas memorables del Principado de Asturias

COBO ARIAS, F., COBES RANBAUD, M., ZARRAClNA VALCARCE, M., 1990,Guía básica de Monumentos Asturianos, Principado de Asturias

CONSEJO DE EUROPA, 1989, "Recomendaciones sobre Patrimonio Rural y Urbano", Revista de Arqueología n 105 , Enero 1990

CORSI, R. 1989, Mattoni e pietre. Le variazioni dimensionali dei laterizi da costruzione a Siena dal XIII al XIX secolo, Tesi di laurea discussa alla Facoltà di Lettere e Filosofia dell'Università degli Studi di Siena.

CORSI, R, 199I, "Forma, dimensioni e caratteristiche del mattone Senese", en Fomaci e mattoni a Siena. Dal XIII secolo all'azienda Cialfi, Cassa Rurale ed Artigiana di Monteriggioni, págs.21-30

COUTTS, P., 1977, "Old buildings tell tales", World Archeology, vol.9, no. 2

EWERT, Ch., CRESSIER, P., ZOZAYA, J., 1990, Coloquio Internacional de Capiteles Corintios Prerrománicos e Islámicos (SS. VI-XII d.C.), Ministerio de Cultura, Madrid

FERRANDO CABONA, I., CRUSI, E., 1979, Storia dell'insediamento in Lunigiana. Alta Valle Aulella, Genova.

FERRANDO CABONA, l., CRUSI, E., 1980, "Costruzioni rurali in Lunigiana: elementi tipo ed evoluzione delle strutture insediative", Archeologia Medievale VII, págs. 250-57

FERRANDO CABONA, l., GARDINI, A., MANNONI, T., 1978, "Zignano I: gli insediamenti e il territorio", Archeologia Medievale V, págs. 273-372

FERRANDO, I., MANNONI, T., PAGELLA, R., 1989 , "Cronotipología", Archeologia Medievale XVI, págs.

FOSSATI, S., 1985, "La datazione dei mattoni: una proposta di metodo", Archeologia Medievale XII, págs. 73I36

FRANCOVICH, R., 1988, "Archeologia e restauro dei monumenti. Nota introduttiva", págs. 13-27 en Archeologia e restauro dei monumenti

FRANCOVICH, R., PARENTI, R.,(a cura di), 1988, Archeologia e restauro dei monumenti (Siena, 28-IX, I0-X 1987), All'Insegna del Giglio, Florencia

GARCÍA CUETOS, M. P., 1987, "El historiador de Arte ante el proceso de 'Restauración Monumental'", Liño 7 ,
Universidad de Oviedo, Oviedo, págs. 203 y ss.

GARDINI, A., MILANESE, M., 1979, "L'Archeologia urbana a Genova", Archeologia Medievale V, págs. $129-70$

GRAÑA, A., LOPEZ, J., 1981, "Las construcciones populares", en Enciclopedia Temática de Asturias, vol 8: Etnografía, págs.73-1 I4

GUINEA, M. J., 1991, "Consolidación, mejora y nuevas técnicas de construcción con tierra", págs. 135-42 en Jornadas sobre Restauración y Conservación de Monumentos, Ministerio de Cultura

HARRIS, E. C., 1991, Principios de estratigrafía arqueológica, Barcelona

HERRERA MENÉNDEZ, J.C., TAPIA SUAREZ, G., VILLAMERIEL FERNÁNDEZ, J.C., 1986, "Capiteles, Fustes y Basas en el arte prerrománico asturiano", Actas del primer Congreso de Arqueología medieval española Huesca, 1985, vol. 10, págs 639 y ss.

LATORRE GONZALEZ-MORO, P., 1988, "El sitio histórico de Melque (prov. Toledo). La intervención integrada con una finalidad didáctica", págs. 157-194, en Archeologia e restauro dei monumenti

LEROI-GOURHAN, A., 1989, El medio y la técnica, Madrid, 2 tomos

LLANO, P. de, 1989, Arquitectura popular en Galicia, Colegio Oficial de Arquitectos de Galicia, 2 vols.

MANNONI, T., 1984a, "Metodi di datazione dell'edifizia storica", Archeologia Medievale XI, págs. 396403

MANNONI, T., 1984b, "Analisi di intonaci e malte genovesi. Formule, materiali e cause di degrado", in Facciate dipinte, págs. $14 \mid 49$

MANNONI, T., 1990, "Archeometria: archeografia o archeologia?", Dialoghi di Archeologia VIII- 2, págs. 77 y ss.

MANNONI, T. e L., 1980, "Problemi archeologici della casa rurale alpina. L'Ossola superiore", Archeologia Medievale VII, págs. 301 8

MANNONI, T., CABONA, D., FERRANDO, I., 1988, "Archeologia globale del territorio. Metodi e risultati di una nuova strategia della ricerca in Liguria", Structures de I'habitat et occupation du sol dans les pays Méditerranées: Les Méthodes et l'apport de l'archéologie extensive, RomaMadrid, págs. 43 y ss. 
MANNONI, T., MILANESE, M., 1988, "Mensiocronologia", in Archeologia e restauro dei monumenti, págs. 383402

MILANESE, M., QUIRÓS CASTILLO, J. A., 1993, "Archeologia globale nell'alta Valdinievole (Pistoia)", Notiziario di Archeologia Medievale, e.p.

MIYARES FERNÁNDEZ, A., 1986, "Tipología de paramentos en el románico asturiano. Método de datación arqueológico artístico", Actas del Primer Congreso de Arqueología Medieval Española, vol. I, págs. 425-436

ORTON, C., 1988, Matemáticas para arqueólogos, Madrid.

PARENTI, R., 1988a, "Le tecniche di documentazione per una lettura stratigrafica dell'elevato", págs. 249-279 en Archeologia e restauro dei monument

PARENTI, R., 1988b, "Sulle possibilitá di datazione e di classificazione delle murature", págs. 280-302 en Archeologia e restauro dei monumenti

PLEITE MARTIN, J., 199|, "Exposición de casos prácticos por empresas especializadas: AGROMAN", págs. I0 I-20, en Jornadas sobre Restauración y Conservación de Monumentos, Ministerio de Cultura

POUNDS, N. J.G., 1992, "La vida cotidiana". Historia de la Cultura Material, Madrid

QUIRÓS CASTILLO, J.A., 1992a , "Cronotipologia di portali nell'alta Valdinievole: la montagna Pesciatina (PT)", Archeologia Medievale XIX, págs. 729 y ss..

QUIRÓS CASTILLO, J.A., 1992b, "Produzione di laterizi nell'alta Valdinievole: la Valleriana (s. XVII-XX)", Convegno Pluriattività e Mercati in Valdinievole (XVI-XIX secolo), Buggiano Castello, 27 Junio, e.p.

RIBERA, A., 1989, "Arqueología urbana como marco de una profesión", págs.21-8, en Curso de formación de jóvenes en arqueología urbana, Diputación Foral de Guipúzcoa, Departamento de Cultura
ROLDÁN GÓMEZ, L., 1987, "Aproximación metodológica al estudio de la técnica edilicia romana en Hispania, en particular el Opus Testaceum", Lucentum VI, págs. I0|-22

SALAS, J., 1991, "El Patrimonio construido con tierra: necesidad de su preservación", págs. 129-34 en Jomadas sobre Conservación y Conservación de Monumentos, Ministerio de Cultura

SANTANA EZKERRA, A., 1989, "Arquitectura popular. Tipologías históricas del caserio", págs. 7I-82, en Curso de formación de jóvenes en arqueología urbana, Diputación Foral de Guipúzcoa, Departamento de Cultura

SHENNAN, S., 1992, Arqueología cuantitativa, Barcelona

SOUTO LASALA, J. A., 1986, "Sobre el papel del arqueólogo medievalista en las obras de restauración de monumentos arquitectónicos", Actas del primer Congreso de Arqueología medieval española, Huesca, 1985, vol. 7 , págs. 89 y ss.

TORRO, J., IVARS, J., 1992, "Villas fortificadas y repoblación en el sur del País Valenciano. Los casos de Cocentaina, Alcoi y Penàguilla", III Congreso de Arqueología Mediaval Española, págs. 472-482, tomo ॥ Comunicaciones

VALDÉS, F., 1989, "La Arqueología urbana como concepto", págs. 17-20, en Curso de formación de jóvenes en arqueología urbana, Diputación Foral de Guipúzcoa, Departamento de Cultura

URIA RIU, J., 1967, "Contribución a la historia de la arquitectura regional. Las casas de Oviedo en la Diplomática del S. XIII al XVI", Boletín del Instituto de Estudios Asturianos LX, Oviedo, págs. 3 y ss.

ZIGRINO, L., 1988, Oneta (BG): "Applicazione dell'analisi stratigrafica alla pianificazione urbanistica attuativa", págs. IOI-III en BROGIOLO, Archeologia dell'edilizia storica 


\section{RESTAURACION Y REHABILITACION ARQUITECTONICA}

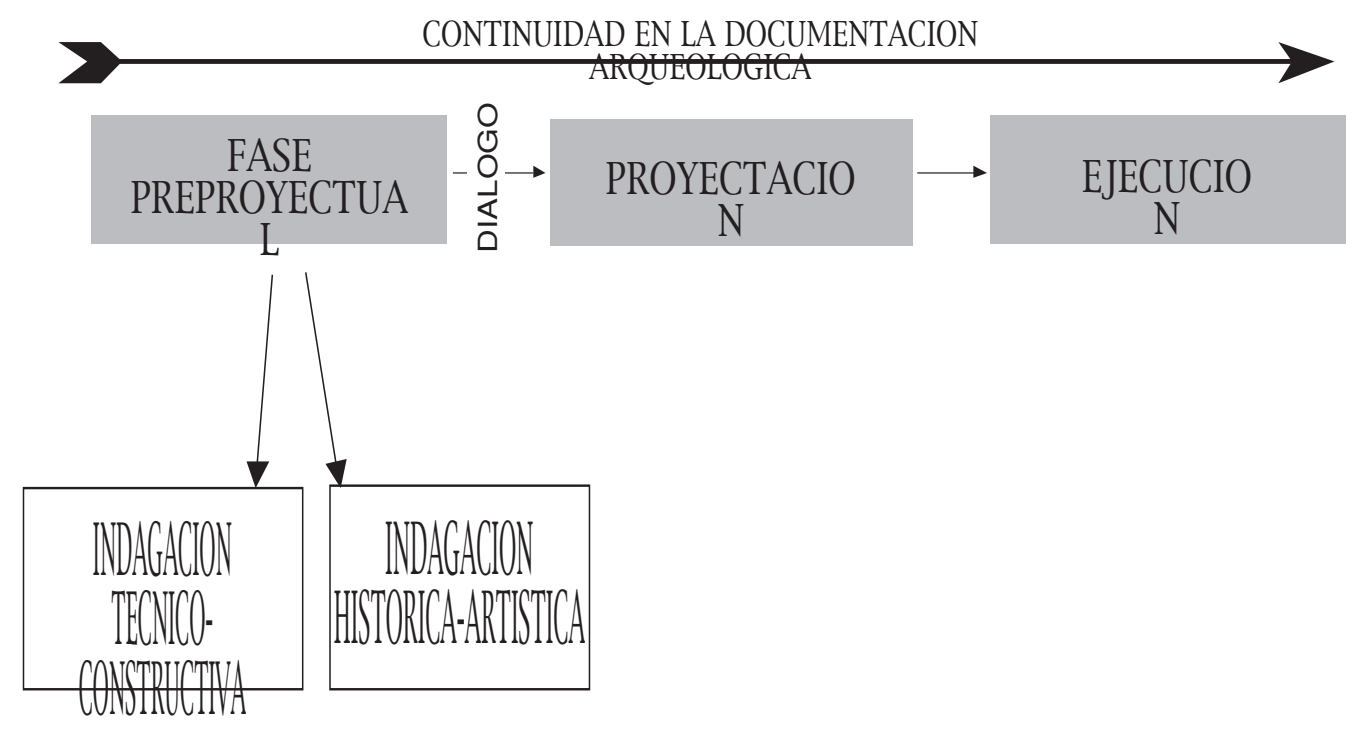

Fig. I. Etapas de la restauración y rehabilitación arquitectónica

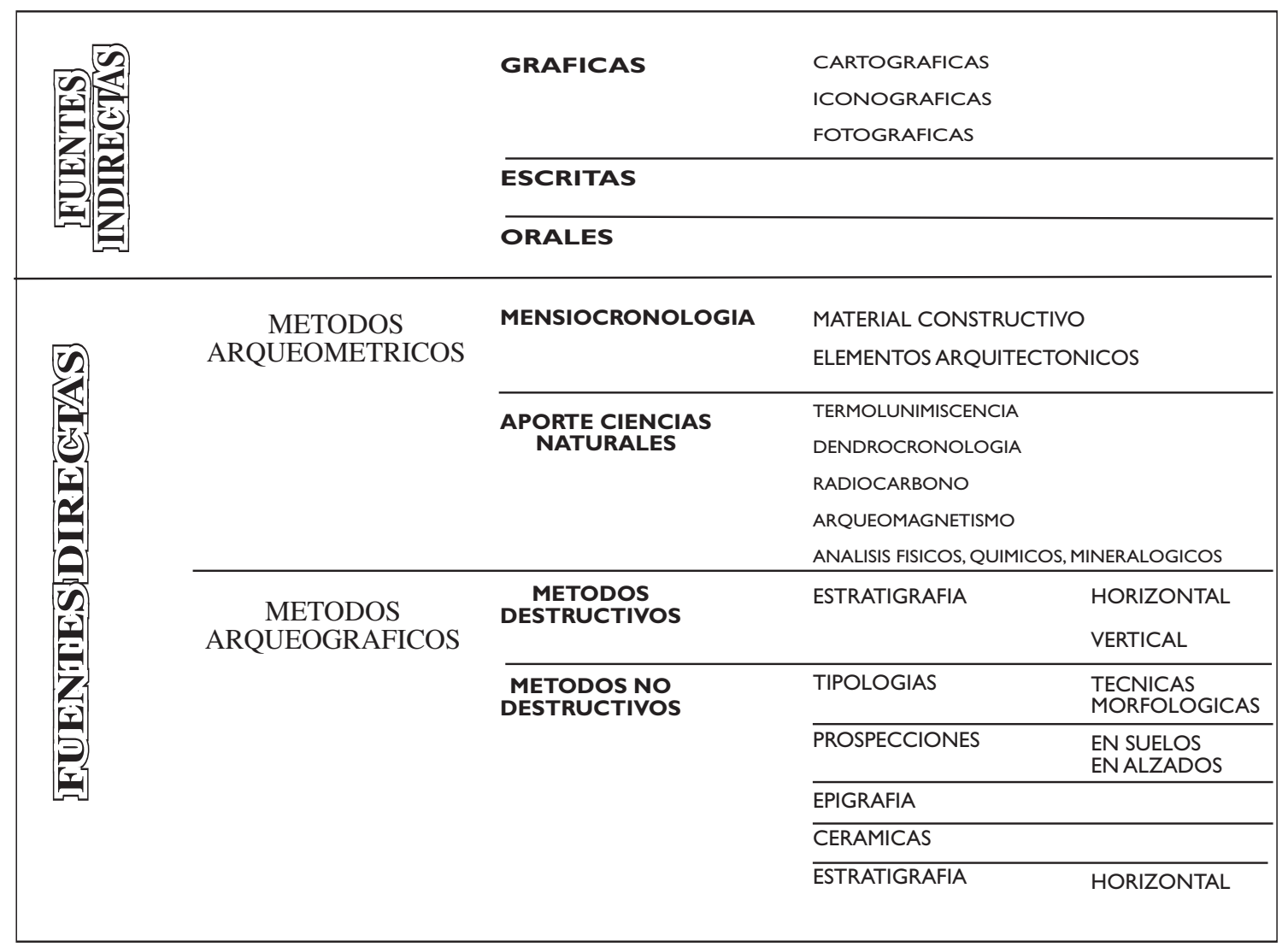

Fig. 2. Tabla de indicadores cronológicos para la arquitectura 

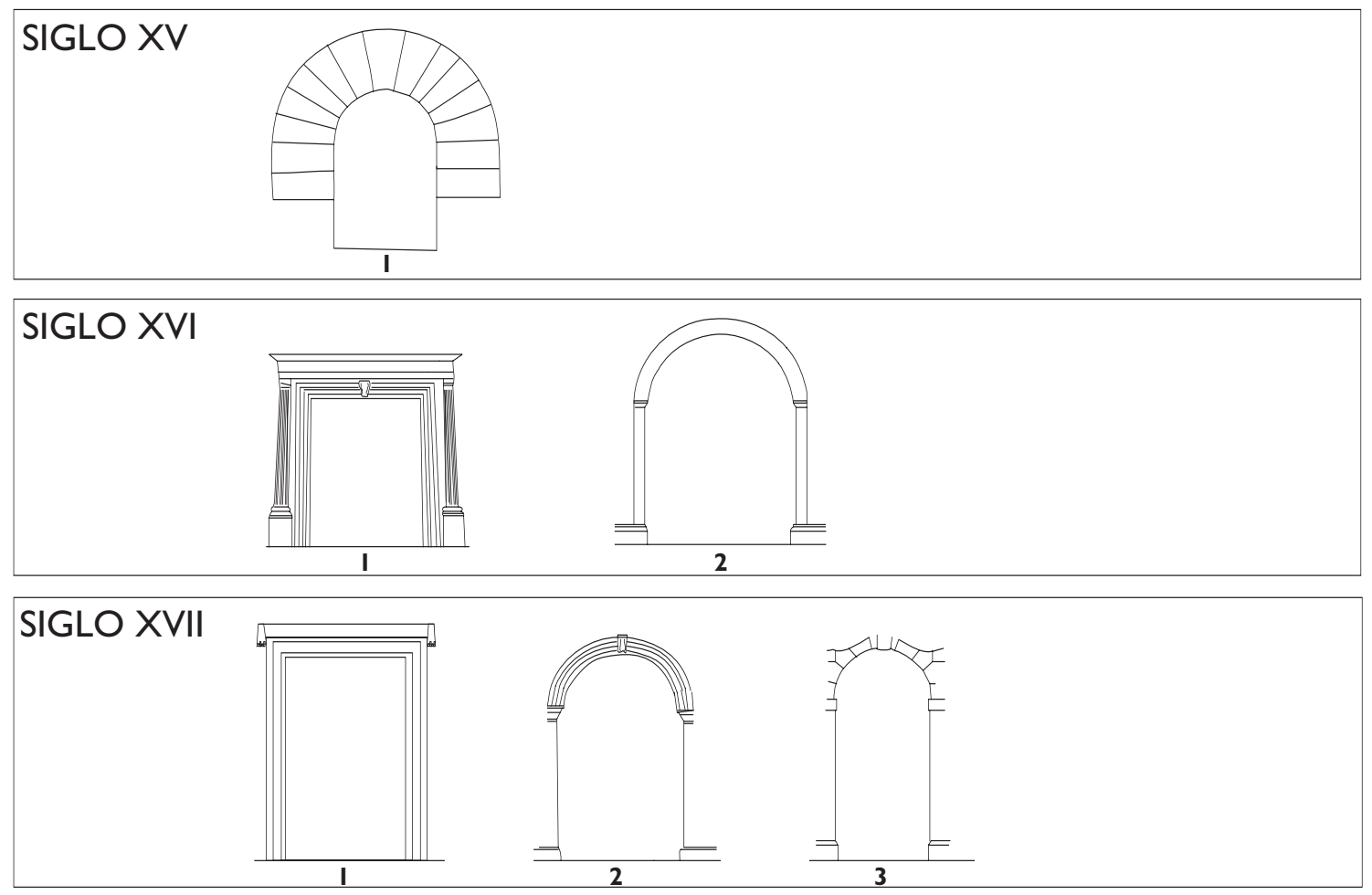

\section{SIGLO XVIII}
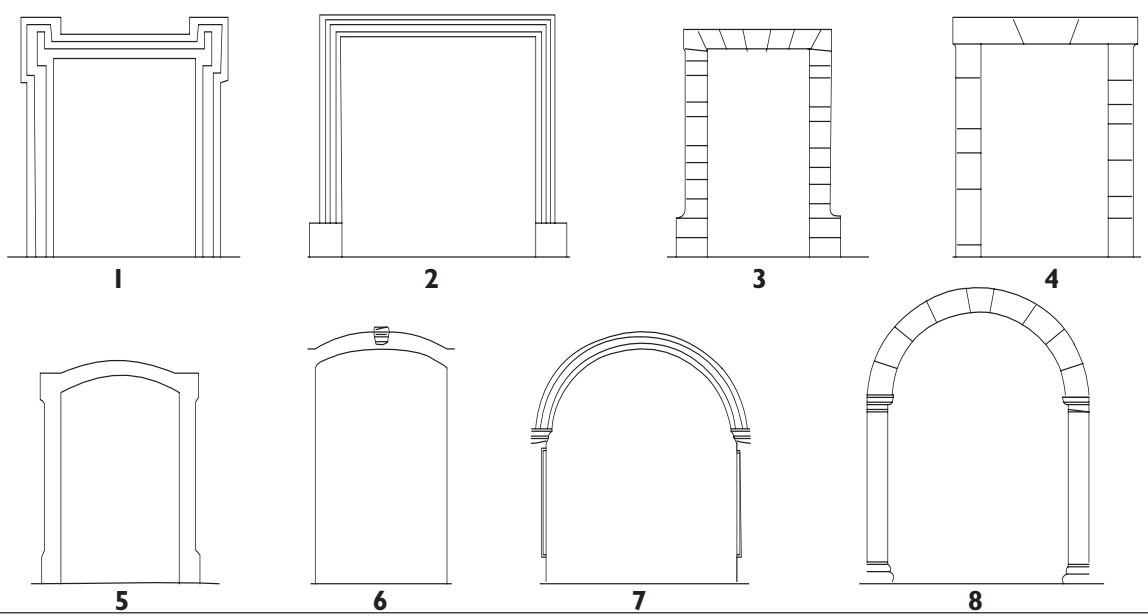

SIGLO XIX

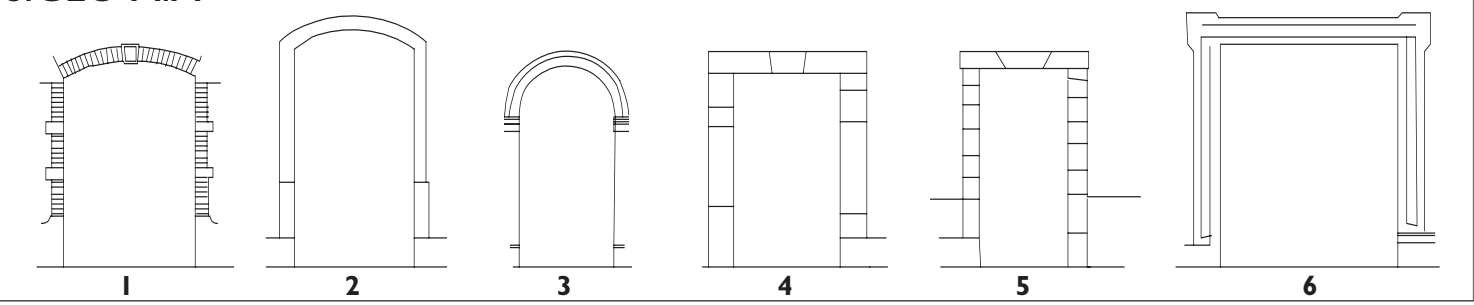

SIGLO XX
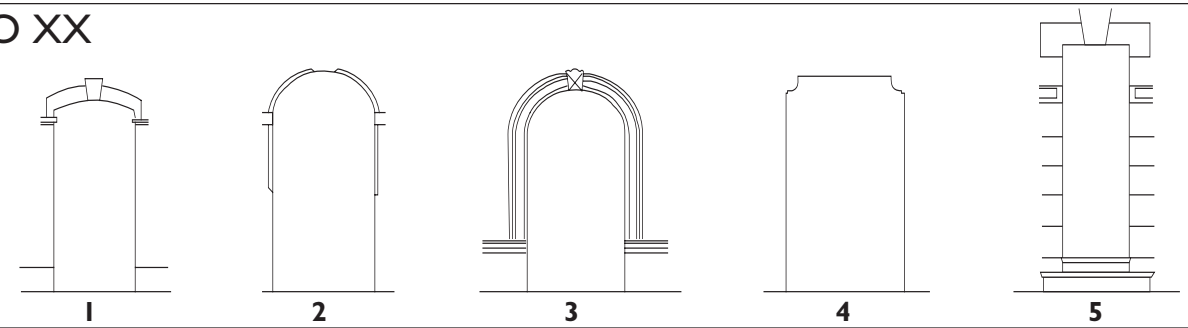

Fig. 3. Cronotipología de puertas de la ciudad de Oviedo (s. XV - XX) 
LOCALIDAD OVIEDO

AYUNT OVIEDO

DIRECCION CIFUEROS 8

EL.DATANTEINSCBIPCION (FD)

TIPOLOGIA XVIII-4

TECNICA JUNTASIRREGULARES

Fото 54

TRATSUPERF

MATERIAL ARENISCA

CONSERVACION OPTIMA-RECONSTB BEC,

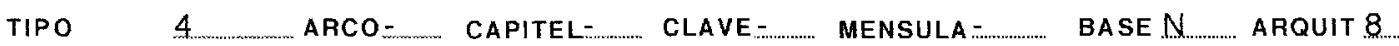

INSTRUM ACABADO CINCEL GBADINA

ARGAMASA AMARILLENTA, DURA, ARIDOS FLUYIALES

BIBLIO EXC Arq Ast

1992 p. 261

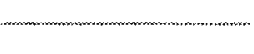

DIBUjo

$\mathrm{OSI}$

ONO

FECHA 25/4/93

CONTROL

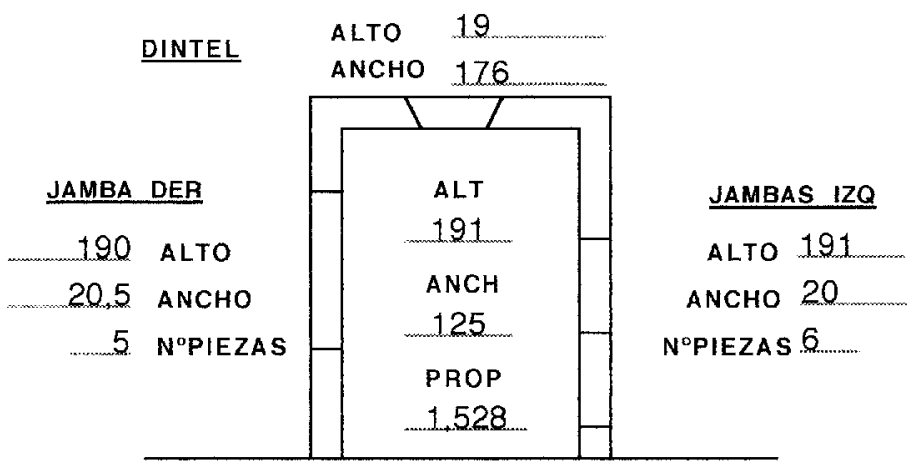

Fig. 4. Modelo de ficha de recogida de datos de puertas datadas

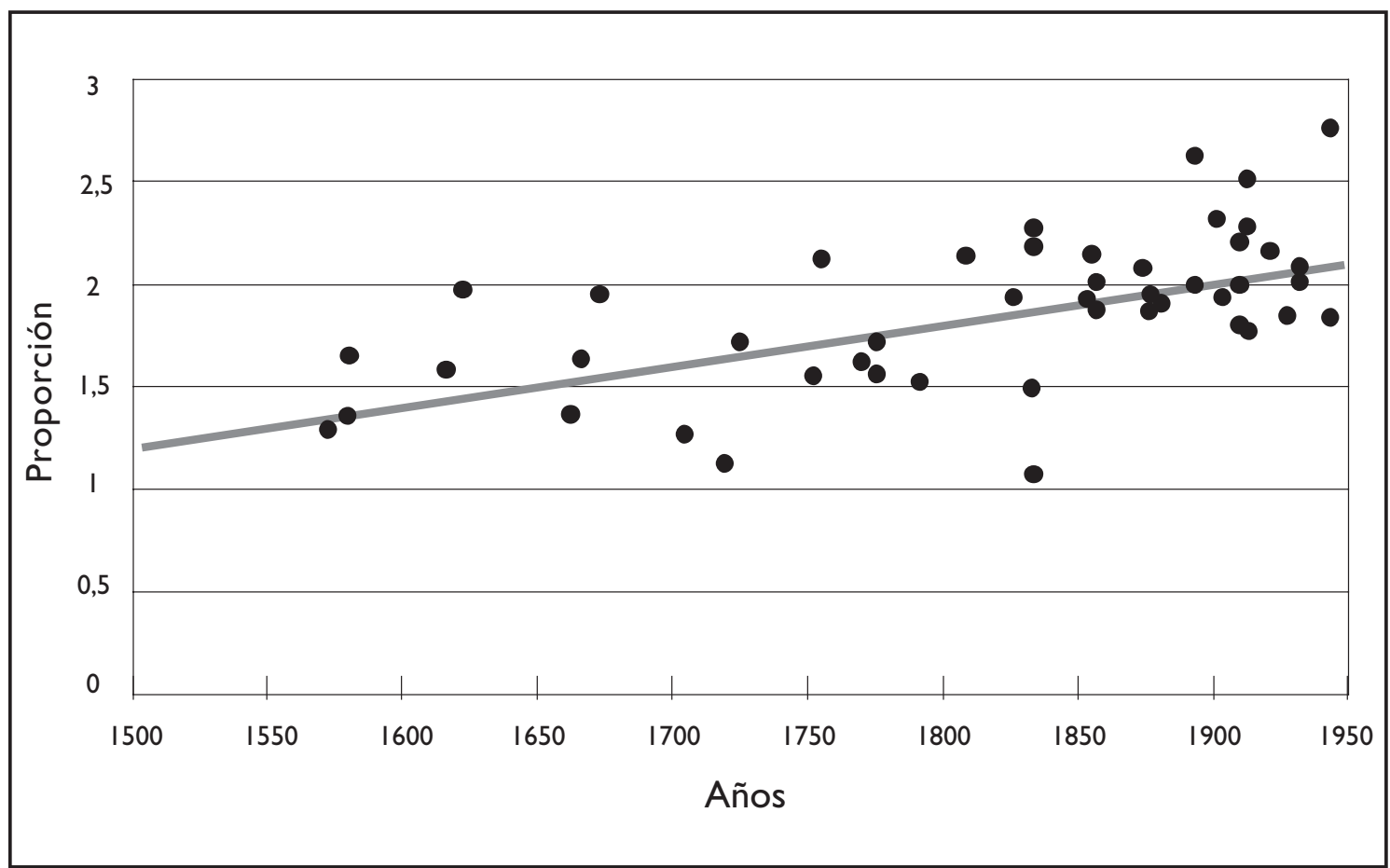

Fig. 5. Variación dimensional en el tiempo de la proporción existente entre las medidas de los vanos de las puertas de Oviedo (alto y ancho) 